\title{
Nachruf
}

Monika Bütler*

\section{Gebhard Kirchgässner - Finanzwissenschaftler, Empiriker, Brückenbauer}

„On Minimal Morals“, „Econometric Estimates of Deterrence of the Death Penalty: Facts or Ideology?“, „Introduction to Modern Time Series Analysis“, „The Effect of Direct Democracy on Income Redistribution: Evidence for Switzerland“, „Kaderschmieden der Wirtschaft und/oder Universitäten? Der Auftrag der Wirtschaftsuniversitäten und -fakultäten im 21. Jahrhundert“. Man würde kaum glauben, dass ein einzelner Wissenschaftler diese schwindelerregende Breite von Themen abdecken könnte. Gebhard Kirchgässner konnte das. Es ist mithin kein Wunder, dass seine Emeritierung im Jahr 2013 die Universität St. Gallen (HSG) vor ein unlösbares Problem stellte. Es hätte mindestens drei Wissenschaftler gebraucht, um die Lücken zu schließen.

Noch viel größer wurde die Lücke am 1. April dieses Jahres. Auf den Tag genau 25 Jahre nach seinem Eintritt in die HSG ist Gebhard Kirchgässner nach schwerer Krankheit im Alter von nur 68 Jahren gestorben. Die Universität St. Gallen, der Verein für Socialpolitik und die Volkswirtschaftslehre als Disziplin verlieren in ihm nicht nur einen brillanten Volkswirt und engagierten Lehrer, sondern auch eine moralische Instanz und einen Brückenbauer zwischen verschiedenen akademischen Fächern, zwischen Theorie und Praxis.

Gebhard Kirchgässner hatte an der Universität Konstanz studiert und wurde dort auch promoviert. Nach seiner Habilitation in Konstanz und an der ETH Zürich wirkte er als Oberassistent an der ETHZ, bevor er 1985 als ordentlicher Professor für Finanzwissenschaft an die Universität Osnabrück berufen wurde. 1992 schließlich folgte er einem Ruf an die Universität St. Gallen, an der er bis zu seinem Tod wirkte.

Trotz seines - aus heutiger Perspektive - vergleichsweise traditionellen Werdegangs war Kirchgässner ein Vertreter der modernen Generation von Volkswirtschaftsprofessoren: forschungsorientiert und international ver-

*Kontaktperson: Monika Bütler, Universität St. Gallen (HSG), Schweizerisches Institut für Empirische Wirtschaftsforschung SEW, St. Gallen, E-Mail: monika.buetler@unisg.ch

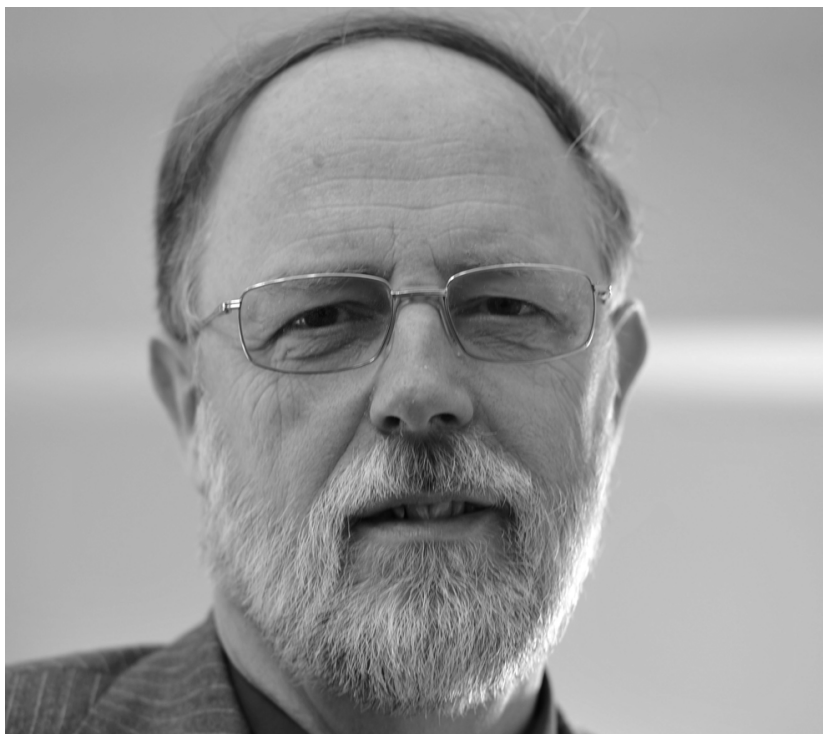

netzt. Zusammen mit Kollegen leitete er die Erneuerung der volkswirtschaftlichen Abteilung ein. Ganz besonders am Herzen lag ihm dabei die Öffnung der einstigen volkswirtschaftlichen Abteilung zu einer international ausgerichteten und interdisziplinären „School of Economics and Political Science“, in der Volkswirte und Politikwissenschaftler gemeinsam wirkten.

Die neue politische Ökonomie, die angewandte Ökonometrie, vor allem aber die Finanzwissenschaft mit all ihren Facetten gehörten zu seinen Hauptforschungsgebieten. Kirchgässner wird als einer der Väter der empirischen Forschung zu Föderalismus und Fiskalpolitik in Erinnerung bleiben. Seine Wahlheimat, die Schweiz, mit ihren dezentralen Entscheidungsstrukturen und der Vielfalt politischer Systeme diente ihm dabei sowohl als Vorbild wie auch als Labor. Der Titel eines 1996 erschienenen, gemeinsam mit dem ebenfalls viel zu früh verstorbenen Kollegen Werner Pommerehne verfassten Aufsatzes lautet: „Tax harmonization and tax competition in the European Union: Lessons from Switzerland“. Schon diese Überschrift lässt es erahnen: Es ging Kirchgässner in seiner Forschung nicht nur um wissenschaftliche Erkenntnisse, sondern auch um die Lehren, die sich daraus für die Wirtschaftspolitik ziehen lassen. 
Damit war er sehr erfolgreich. Seine Arbeiten zu Föderalismus, direkter Demokratie, Steuer- und Ausgabenwettbewerb hatten eine Wirkung weit über die Zitationen in besten wissenschaftlichen Zeitschriften hinaus. Mehr und mehr begann sich auch die Politik für seine Erkenntnisse $\mathrm{zu}$ interessieren. Zahlreiche Doktorandinnen und Doktoranden, die ihn bei diesen Arbeiten begleiteten, sind heute selber erfolgreich in Forschung und wirtschaftspolitischer Beratung im In- und Ausland tätig.

Neben dem Föderalismus war die kritische Auseinandersetzung mit den philosophischen und wissenschaftstheoretischen Grundlagen der Volkswirtschaftslehre Kirchgässners zweites Steckenpferd. Sein 1991 in der ersten Auflage erschienenes, in viele Sprachen übersetztes Buch „Homo oeconomicus: Das ökonomische Modell individuellen Verhaltens und seine Anwendung in den Wirtschafts- und Sozialwissenschaften" ist heute ein Standardwerk. Die Diskussion um Werte und Moral war ihm stets wichtig. Nicht von ungefähr diente er bis vor kurzem dem Verein für Socialpolitik mit Kompetenz und Herzblut als Vertrauensperson der Ethikkommission. Immer wieder hinterfragte er Methode und Inhalte seiner Disziplin im Spiegel der Aktualität, wie sein Aufsatz „Die Krise der Wirtschaft: Auch eine Krise der Wirtschaftswissenschaften?“, erschienen 2009 in dieser Zeitschrift, exemplarisch zeigt.

Kirchgässners Arbeiten fanden international große Beachtung. Seine Aufsätze erschienen nicht nur in wissenschaftlichen Journalen, sondern auch in den Medien und in jüngerer Zeit in Blogs. Geschrieben waren sie immer mit der ihn kennzeichnenden Stringenz und Unbestechlichkeit. Schweizerischen und internationalen Wissenschafts- vereinigungen diente er mit großem Einsatz, zum Beispiel als Präsident der Schweizerischen Gesellschaft für Volkswirtschaft und Statistik, als Präsident der European Public Choice Society und als Mitglied zahlreicher Ausschüsse und Gremien des Vereins für Socialpolitik. Hochverdient wurde er im Jahr 2011 mit dem Ehrendoktor der Universität Freiburg (Schweiz) ausgezeichnet.

Der Dienst an der Gesellschaft war für den Familienmenschen Gebhard selbstverständlich, angefangen vom Wehrdienst über die Mitwirkung in wohltätigen Stiftungen und in der katholischen Kirche, bis hin zur Geschäftsprüfungskommission seiner Wohngemeinde. Bereits vor seiner Einbürgerung, auf die er sichtlich stolz war, diente er seiner Wahlheimat in verschiedenen Funktionen. Er nahm unzählige Beratungsmandate für die Eidgenossenschaft wahr und präsidierte während vieler Jahre die eidgenössische Kommission für Konjunkturfragen. Deren Auflösung 2007 hielt er für einen schweren Fehler und wehrte sich dagegen - erfolglos. Gerade im Hinblick auf schwierigere Zeiten hätte die Schweiz ein überparteiliches Expertengremium gut brauchen können, meinte er. Er behielt wie so häufig Recht.

Gebhard Kirchgässners Prinzipientreue und Aufrichtigkeit waren legendär. Was er sagte, meinte er auch. Und was er meinte, sagte er auch. Er scheute sich nie, unangenehme Wahrheiten auszusprechen, wenn es der Sache diente. Mit seiner Frau Maria, die ihn auf seinem Lebensweg (und zu vielen Veranstaltungen) begleitete, trauern wir um eine große Persönlichkeit, einen spannenden und ehrlichen Gesprächspartner und treuen Freund. Wir werden ihm ein ehrendes Andenken bewahren. 